\title{
LA REVOLUCIÓN DEL PUDOR: ESCÁNDALOS, GÉNERO Y POLIITICA EN LA CRISIS DE LA MONARQUÍA LIBERAL EN ESPAÑA'
}

The revolution of modesty: Scandals, gender and politics in the crisis of the liberal monarchy in Spain

\author{
ISABEL BURDIEL
}

Universitat de València

isabel.burdiel@uv.es

\section{Resumen}

En este artículo se trata de analizar el carácter performativo de los grandes escándalos morales y políticos en torno a la familia real, que afectaron a la imagen pública y a los mecanismos de legitimación de la monarquía liberal en Espańa durante el reinado isabelino. Abordo el tema desde la perspectiva actual de reflexión sobre la imbricación histórica de las nociones de virtud política y escándalo moral que dio lugar a la idea de "corrupción» en el universo liberal. Una idea que, como trato de demostrar, tuvo fuertes connotaciones de género, estuvo ligada a la dinámica de

1 Este artículo se ha realizado en el marco del proyecto investigación HAR-53802 2014-P: «Construcciones del yo: Narraciones y representaciones del sujeto moderno entre lo personal y lo colectivo, siglos XVII-XIX». 
construcción del Estado nación, obliga a una ampliación sustancial de nuestra noción de «lo político», sugiere el carácter históricamente creativo de los escándalos y demuestra las formas heterodoxas, no necesariamente públicas o convencionalmente «razonables», que fueron conformando, en la práctica, la opinión pública y el régimen de publicidad modernos.

\title{
Palabras clave
}

Monarquía; liberalismo; escándalos; nación; género.

\begin{abstract}
This article analyzes the performative nature of the great moral and political scandals built around the royal family, which affected the public image and the mechanisms of legitimation of the liberal monarchy in Spain during the reign of Isabel II (1833-1868). I approach the subject from the current perspective of reflection on the historical overlapping of the notions of political virtue and moral scandal that gave rise to the idea of "corruption" in the liberal universe. An idea that, as I have tried to demonstrate, had strong gender connotations, was linked to the nation-state building dynamics, forces a substantial extension of our notion of the political, suggests the historically creative nature of scandals, and demonstrates the heterodox, not necessarily public or conventionally "reasonable" forms, which shaped the very notion of modern public sphere.
\end{abstract}

\section{Keywords}

Monarchy; liberalism; scandals; nation; gender. 


\section{SUMARIO}

I. INTRODUCCIÓN. II. MONARQUÍA Y NACIÓN EN LA ÉPOCA DEL LIBERALISMO. III. ¿̇EMOCIONES PREPOLÍTICAS? IV. APOLO Y DIONISIO: LA CARA OCULTA DEL RÉGIMEN DE PUBLICIDAD MODERNO. V. TRANSGRESIÓN Y REACCIÓN. MATERIALES DE ESTUDIO. VI. Y UNA SERIE DE PREGUNTAS. BIBLIOGRAFIA.

\section{INTRODUCCIÓN}

El 17 de octubre de 1868, en el periódico republicano La Discusión, Félix Pyat escribió:

Habéis despedido una mujer... iperdonad! Una reina, llaga de su pueblo, vergüenza de su sexo, escandalosa calamidad, cúmulo de todas las liviandades de un hombre, sin una sola virtud de mujer; con todo los vicios públicos, sin una sola virtud privada; con todos los pecados de una Magdalena, sin uno de sus remordimientos; beata que del confesionario ha ido al lupanar; cristiana con un serrallo de hombres; Luis XV hembra con su parque de rumiantes, que ha convertido $[. .$.$] su lecho en trono y sus queridos en vuestros reyes. Ésta es la$ revolución del pudor ${ }^{2}$.

Un mes antes, el 16 de septiembre, la escuadra y los cuerpos del ejército sublevados en Cádiz contra la reina Isabel II emitieron un manifiesto a la nación en el que se leía: «Ya basta de escándalos [...] Queremos que las causas que influyan en las supremas resoluciones las podamos decir en voz alta, delante de nuestras madres, de nuestras esposas y de nuestras hijas: queremos vivir la vida de la honra y de la libertad [...] ¡Viva España con honra! ${ }^{3}$.

Ambos documentos — procedentes de entornos políticos muy distintos- establecieron en su momento una relación estrecha entre lo que un folleto de época llamó Los escándalos de Isabel II (1854) y la revolución de 1868 que forzó su abdicación. Con ella, se ponía en cuestión el modelo de monarquía constitucional establecido en España durante los convulsos años treinta del siglo XIX. Este artículo tiene el carácter de una propuesta metodológica que trata de explorar — sobre la base, en parte, de evidencia empírica tratada

2 La Discusión, 17-10-1868.

3 Morayta (1893-1894): 541-542. 
desde otro enfoque en trabajos anteriores - los patrones culturales, morales y de género que estuvieron implicados en la construcción política de esos escándalos, o que surgieron de manera nueva en la discusión de los mismos ${ }^{4}$. Con ello pretendo contribuir al análisis de las formas paradójicas — es decir, aparentemente contradictorias- que adoptó en España la gran batalla política entre la monarquía y el liberalismo durante el siglo XIx. En ese proceso, como en toda Europa, desempeñó un papel crucial (y aún escasamente estudiado) la conformación histórica de "lo escandaloso", tanto en términos morales como políticos y económicos. A través esos «escándalos» se forjaron mecanismos de crítica y movilización políticas altamente emocionales y sumamente operativos que contribuyeron a consolidar la ruptura liberal con la vieja monarquía procedente del Antiguo Régimen.

Desde un punto de vista más general, trato de argumentar tres cuestiones estrechamente relacionadas entre sí. Por una parte, la necesidad de cuestionar la noción clásica de esfera pública o de régimen de publicidad liberal. Por otra, las formas concretas de resignificación de las fronteras entre lo público y lo privado que implica ese cuestionamiento. Por último, el carácter performativo, históricamente creativo, de los escándalos llamados sexuales. Todo ello puede ayudar a ampliar nuestra noción de «lo político», incluyendo variables culturales capaces de hacerse cargo de la interpenetración entre pasiones e intereses, emociones y razón en la lucha política.

\section{MONARQUÍA Y NACIÓN EN LA ÉPOCA DEL LIBERALISMO}

En estos momentos ya se ha dejado atrás, historiográficamente hablando, una imagen de la monarquía decimonónica como una institución obsoleta, antimoderna: una reliquia del pasado, ajena (cuando no un obstáculo) a los procesos de cambio del siglo XIX. Como ha escrito Dieter Langewiesche, la monarquía constitucional fue vista (y se vio a sí misma) como parte integrante de la imagen de progreso y seguridad característica del siglo XIX europeo hasta la Gran Guerra: «El siglo burgués, el siglo de la nación y del estado nacional [...] era también el siglo de la monarquía [...] una fuerza política y cultural de integración a la que prácticamente ninguna de las naciones de Europa quería renunciar" ${ }^{5}$.

Sin embargo, hasta hace relativamente poco, el análisis histórico de los materiales culturales de esa fuerza de integración monárquica (y de los

\footnotetext{
4 Burdiel (2010 y 2012).

5 Langewiesche (2012): 210 y Banerjee et al. (2017).
} 
conflictos suscitados en torno a ella) ha sido marginado en favor de los estudios estrictamente políticos o de teoría constitucional. La renovación de la historiografía al respecto viene demostrando que la compatibilidad (y la pugna) entre monarquía y liberalismo se dirimió, en aspectos estratégicos, dentro del ámbito de lo cultural y emocional en su acepción más amplia. Los cambios al respecto no se produjeron en planos separados, desarrollados de forma paralela o subordinados de forma lineal y mecánica unos a otros. Por el contrario, se cruzaron de forma constante, reforzándose u obstaculizándose, y lo que fue más decisivo, simbolizándose mutuamente ante la opinión pública ${ }^{6}$.

La resistencia de todos los monarcas a perder poder sobre su comportamiento privado (tanto en lo económico como en lo sexual) se entrecruzó frecuentemente con la tensión política entre la Corona y el Parlamento y con la pugna sobre las formas posibles de representación simbólica de ambos en relación con las aspiraciones, los valores, la moralidad y las costumbres nacionales. Valores, moralidad y costumbres que se fueron construyendo al tiempo que se construían los Estados nación que, en toda Europa occidental, constituyeron el marco político y cultural de la modernidad posrevolucionaria. Las experiencias fueron plurales pero, en todos los casos, la consolidación de «la libertad de los modernos» —en palabras del gran teórico de la monarquía constitucional que fue Benjamin Constant- implicó una necesaria «nacionalización» de la monarquía, y del monarca, en competencia o de consuno con el Parlamento como representante de la soberanía, tanto en términos políticos como simbólicos. En ese contexto, como dijo Adolphe Thiers, reinar «es ser la imagen más verdadera, la más alta, la más respetada del país» 7 . Una fórmula que, tras su aparente rotundidad, resultó siempre muy ambigua y suscitó un desconcierto político que, durante todo el siglo xix, fue consustancial a la monarquía constitucional. Un tipo de monarquía que, en este sentido fundamental, conviene no confundir con la monarquía parlamentaria o democrática posterior. La cuestión no quedó jamás resuelta en la práctica y, de hecho, se convirtió en el núcleo de la tensión constante entre los poderes del rey y los poderes de la nación. Una tensión que estuvo ligada en todas partes a la reelaboración posrevolucionaria de las claves de identidad nacionales, las cuales fueron dominando todas las imágenes de comunidad política, social o cultural. En ese escenario, tanto la nueva monarquía como la nación se reinventaron conjuntamente ${ }^{8}$.

6 Deploige (2007).

7 Adolphe Thiers, Le National (1830), citado en Rosanvallon (1994): 157.

8 Anderson (1993); Kirsch (1999); Blanco Valdés (2010); Brice (2010), y Brice y Moreno Luzón (2013). 
La historiografía reciente ha ido despojando a ese proceso del sentido más burdamente funcionalista que ciertas lecturas de las obras pioneras de Benedict Anderson, David Cannadine o Eric Hobsbawm pudieron propiciar en su momento?. Tanto la tradición monárquica como la nación fueron algo más que «invenciones» puras y simples. Viejos lenguajes, tradiciones, valores y sentimientos de pertenencia previos se reelaboraron y reorganizaron hasta construir algo tan solo parcialmente nuevo. Por ello, para entender la monarquía «moderna» es necesario ver de dónde viene, qué hábitos, comportamientos y símbolos quedaron adheridos a ella y gobernaron sus acciones (así como las de su entorno respecto a ella) de forma que, aunque para ciertos sectores podían resultar cada vez más anacrónicos, eran aún operantes cultural y políticamente para otros.

Esta cuestión es singularmente importante en lo que se refiere al comportamiento privado del monarca y a su representación pública de forma (o no) escandalosa. Resulta evidente que todos los reyes y reinas del siglo XIX, con diversos grados de resistencia y de éxito, se vieron forzados a adecuar su comportamiento político y privado (y la representación de ambos) a las reglas morales de la nueva sociedad burguesa y liberal que pugnaba por establecer su autoridad, tanto política como moral, sobre la vieja institución. Un proceso que trasciende los mecanismos oficiales de la monarquía ceremonial o escénica - la performing monarchy de los pioneros estudios ingleses - ${ }^{10}$.

El camino abierto por estos, hace ya más de treinta años, ha comenzado quizás a obedecer a la ley de rendimientos decrecientes. En buena medida, porque seguimos sabiendo demasiado poco respecto a la recepción de esas grandes representaciones monárquicas y sobre los conflictos de significación que podían producir en sociedades cada vez más diferenciadas social y políticamente. Menos sabemos, si cabe, de la diseminación social continua, soterrada y diaria, de materiales culturales capaces de recordar constantemente a los ciudadanos su pertenencia a una nación monárquica. Desde el teatro a la literatura, pasando por las cartas de visita, la propaganda comercial, el arte, los sellos de correo o los chistes, hay una serie de materiales que apenas han sido abordados a la hora de analizar el cruce de las dinámicas ascendentes y descendentes, legitimadoras y deslegitimadoras, del nacionalismo y el monarquismo «banales». Un entramado político-cultural sumamente complejo que —además de servir para desnaturalizar tanto la monarquía como la naciónconviene analizar como parte de una problemática común de carácter transnacional en la que los trasvases fueron muy habituales en toda Europa ${ }^{11}$.

\footnotetext{
9 Anderson (1993); Cannadine (2004), y Hobsbawm (2002).

10 Cannadine (1983); Deploige (2007), y Unowsky (2005).

11 Billig (1998); Deploige (2007); Plunkett (2002), y Brice (2010).
} 
Por otra parte, como señaló en su momento Louise Olga Fradenburg, los estudios sobre el poder monárquico seguirán siendo inadecuados si no se analiza la forma en que la propia noción de soberanía real incluye fuertes connotaciones de género $^{12}$. Los significados culturales asociados a la diferencia sexual, la familia y el matrimonio permearon todo el ordenamiento político liberal. A pesar de sus diferencias internas, que pudieron ser muchas y cambiantes, esos significados tendieron a negar la independencia no solo política, sino moral de cualquier forma de poder, y en concreto del poder monárquico, respecto a la voluntad soberana de la nación y sus valores dominantes. Pretendo argumentar, a través del análisis de algunos de «los escándalos de Isabel II", la importancia que estos tuvieron para poner en evidencia las crisis de autoridad de la nación sobre la reina y las formas de que se valió la primera para hacerse presente y reforzar esa autoridad en peligro. El singular de «nación» es aquí meramente operativo y a lo largo del análisis espero poder subrayar la heterogeneidad y el carácter cambiante de sus manifestaciones hasta confluir en el relativo consenso moral y político que propició la llamada Gloriosa Revolución de 1868. Un consenso que se forjó en torno a materiales culturales tan diversos $-\mathrm{y}$ heterodoxos respecto a los más convencionales de la prensa o el debate parlamentario — como la llamada "ficción doméstica» de las novelistas morales o la pornografía política que circuló ampliamente durante el reinado isabelino. Lo que me interesa, por lo tanto, es situar la conformación de una esfera pública nacional en el debate político posrevolucionario en relación con respuestas morales y emocionales escasamente tenidas en cuenta en los estudios de carácter político tradicional.

\section{III. ¿EMOCIONES PREPOLÍTICAS?}

El 30 de enero de 1847, el diplomático y escritor Juan Valera, con buenas conexiones entre la alta sociedad y en la corte, escribió a su padre:

Las noticias políticas las sabrá usted por los periódicos, excepto aquellas que, por su carácter reservado, no se pueden publicar. Lo más notable que hay sobre este particular son los disgustos y pendencias de Palacio, que se van haciendo

12 Fradenburg (1992). Se han realizado ya muchos trabajos en esa dirección para el período que nos ocupa. Véanse por ejemplo Munich (1996); Homans (1998); Cosandey (2000); Shulte (2002); Goodman (2003); Campbell (2007); Burr Margadant (2006); y para la España decimonónica, Burdiel (2012 y 2015) y Gutiérrez et al. (2014). 
escandalosos, y en particular desde hace unas noches. La Reina dio un baile y, como el mismo día había tenido gran disputa con su esposo, salió casi llorando a recibir a la sociedad, y don Francisco de Asís no quiso salir y se estuvo picado y encerradito en su cuarto, y aquella noche no durmió ni visitó a su señora. Esto da motivo a infinitas hablillas y las damas de buen tono dicen que no será extraño que Su Majestad hembra busque algún consuelo, y la disculpan para cuando lo haga, con la estúpida conducta de su marido. También añaden [...] otras mil majaderías, increíbles unas y creíbles otras ${ }^{13}$.

En la primavera de ese mismo año, las predicciones de las damas de palacio se habían cumplido sobradamente y la reina malcasada vivía un sonoro romance con el general Serrano, cuyas tendencias liberales parecía que podían poner en peligro el régimen muy moderado inaugurado en 1845. Así lo interpretaron las clases populares de Madrid, que, al igual que las damas de la corte, consideraban que la actitud del rey provocando un conflicto público por el desvío privado de la reina era extemporánea e injustificada. En ambos casos, su moral en estos asuntos era mucho más flexible que la moral burguesa (o que el discurso burgués sobre la moral sexual) que preconizaba para «todas» las mujeres los valores de la castidad, el pudor, la templanza y la fidelidad matrimonial. De hecho, en 1847 , la satisfacción de amplios sectores populares ante el affaire Serrano alarmó incluso a los notables progresistas que hubieran podido extraer rentabilidad política del favorito de la reina y del divorcio de esta.

La reacción popular, que no implicaba necesariamente una postura promonárquica sostenida y definida como tal, respondía a un relato ampliamente difundido sobre la familia real en general y sobre la reina en particular. Un relato que enfatizaba la injusticia cometida con una adolescente casada contra su voluntad con un hombre tildado públicamente de afeminado y del que además (aquí sí la connotación política era crucial) se conocían sus simpatías carlistas. Razones morales y políticas se retroalimentaban entre sí. Aquel matrimonio «inmoral», "contra natura», había violentado tanto la inocencia de la reina como la del pueblo liberal que había luchado en la guerra civil por sus derechos frente al infante don Carlos y el absolutismo. La opresión, la violencia y la pérdida de libertad que había sufrido el liberalismo popular desde la subida al poder de los moderados en 1843-44 — apoyados por la muy odiada exregente María Cristina- permitía una comparación estratégica y de fuerte contenido emocional con la imagen que existía entonces de una reina casi nińa, forzada a aceptar un matrimonio y una opción política que se

13 Valera (2002): 41. 
consideraban impuestas sobre ella. La intensa politización que se había producido durante los años de la ruptura liberal buscaba así, en condiciones de dura represión y exclusión política de las opciones progresistas y radicales, un cauce de expresión y movilización moral para su descontento político.

Las salidas de la reina por Madrid, acogidas desde su matrimonio con Asís con gran frialdad, empezaron a suscitar un entusiasmo inaudito. En el Teatro del Príncipe fue rodeada "por una turba de gentes de dudoso aspecto, que la saludó frenéticamente». En los toros se desplegó un enorme abanico que por una cara decía "Viva la Reina» y, por la otra, "Constitucional», acabando la corrida con una manifestación de alegría que salió de la plaza cantando el Himno de Riego, con toda su simbología revolucionaria y radical, vitoreando a la reina y a Serrano y gritando «mueras» al general moderado, Narváez, y a su aliada política la reina madre, María Cristina de Borbón.

Un mal trazado, con marsellés al hombro y sombrero gacho en la cabeza [traje muy usado entonces por la gente flamenca] subió al coche de la reina y durante un largo rato fue diciéndole flores y frases picantes que la hicieron reír no poco, y otros, obsequiándola con piropos y saetas, tan comunes entre los maleantes y desocupados. El principal pecado de aquellos entusiasmados consistió así en tratar a la reina como a mujer, cosa en verdad que a ella no ofendión ${ }^{14}$.

Como mujer, y como reina, Isabel II tenía derecho a ser apoyada en sus intenciones de divorcio y, supuestamente, de cambio de rumbo político. Insisto en que manifestaciones de este tipo no prejuzgan la popularidad de la monarquía en la España de la época; un tema necesitado aún de mucha más investigación empírica. Sí apuntan, sin embargo, hacia las formas en que pudo manifestarse, en condiciones de participación profundamente oligárquicas, la voluntad de protagonismo político de las clases populares y la serie de valores y emociones que, en ese momento, se podían asociar (o no) a la nueva monarquía constitucional.

Las similitudes con el affaire de la reina Corolina en la Inglaterra de finales del siglo XVIII, cuando se produjo una insólita movilización popular contra del deseo de Jorge IV de divorciarse de su esposa e inhabilitarla políticamente, son evidentes. En ambos casos, los escándalos sexuales en torno a la familia real fueron mucho más que manifestaciones premodernas, o prepolíticas, para apuntar directamente a la primacía de la nación, y de sus valores morales, sobre la Corona. Como todos los escándalos, desempeñaron una función de control social, de jerarquización nueva de valores, de regeneración del grupo.

14 Diario de Sesiones de Cortes, 12 de abril de 1847 y Morayta (1893): 118 y ss. 
Por ello, no fueron anomalías disfuncionales, o manifestaciones de irracionalidad política banales, sino momentos políticos creativos y altamente significativos $^{15}$.

Lo interesante aquí es la forma en que ese tipo de movilizaciones — que durante mucho tiempo han sido juzgadas inexplicables, y denigradas, por la historia social clásica - buscaba asentar una autoridad primordial sobre las reglas básicas de lo político que ampliaban sustancialmente su concepción clásica y fundamentalmente elitista. Eran formas de reafirmación de los valores compartidos sobre qué cosa habría de ser la virtud política de manera que, como ha señalado Antoine Lilti, formaban parte de la propia configuración de un público que tomaba conciencia de sí mismo, imponía su presencia y participaba en su propia formación. Fueron por lo tanto, a mi juicio, momentos fundacionales del régimen de publicidad moderno ${ }^{16}$. Un atento observador de la cultura política popular en la España de entonces, el antiguo conspirador liberal Eugenio de Aviraneta, escribió:

El que diga que estamos sin civilizar que corra a las tabernas, las plazas, las carbonerías y los barrios bajos, y verá hombres y mujeres llenos de andrajos disputando sobre la Reina, el Rey, Montpensier, Mon, Pidal, Salamanca, Benavides, Espartero y el sistema tributario. Así es la época y habremos llegado a la de la política en la cual hasta los zapateros de viejos se creen estadistas consumados ${ }^{17}$.

Escándalos de este tipo cuestionaban además la definición liberal de esfera pública, y de opinión pública, como el reino apolíneo de la razón crítica, inmediatamente transparente, frente al impacto político de lo emocional, de lo privado y también de lo clandestino. Esta última consideración es fundamental para entender el carácter ambivalente, y sumamente resbaladizo, de los factores de deslegitimación (o relegitimación) de la monarquía que introducían los que hoy llamaríamos "escándalos sexuales» en el nuevo escenario del liberalismo o, más exactamente, de las pugnas internas del liberalismo por imponer uno u otro modelo de monarquía. Fueron luchas por el poder simbólico que cruzaban las fronteras entre lo político y lo privado a través de supuestos morales vinculantes entre ambos ámbitos. Un vínculo que se creaba al mismo tiempo que se invocaba como justificación del conflicto. En

15 Clark (2004) y De Blic y Lemieux (2005).

16 Lilti (2014) y, aunque discutiendo la cesura que parece establecer entre el reinado isabelino y la Restauración borbónica en España, Capellán (2015).

17 Archivo Histórico Nacional, Diversos, Títulos y Familias, leg. 3539/3.3, doc. 16. Eugenio de Aviraneta a Fernando Muñoz, 8 de agosto de 1847. 
ese escenario es crucial evitar contraponer de forma mecánica las supuestas disfunciones morales de la familia real con los valores burgueses y liberales sobre la familia y la feminidad respetables, como si estos últimos fuesen homogéneos, estáticos y plenamente definidos al margen del conflicto sociocultural y político de la época. Por el contrario, la discusión (o más exactamente las múltiples y a menudo contradictorias valoraciones) sobre la vida íntima de la reina y de su entorno formaron parte de la conformación de dichos valores en su pugna global contra la degradación moral de las formas de vida aristocráticas, cuya representación máxima en el imaginario popular habría de quedar fijada en los llamados «misterios de Palacio»"

La imagen idealizada de la reina Isabel, que aún pervivía en los sucesos que he expuesto más arriba, comenzó a quebrarse relativamente pronto con el paso de los ańos y los avatares de la lucha política entre los diversos liberalismos que pugnaron por controlar el poder de la Corona a lo largo del reinado $^{19}$. El liberalismo moderado logró sin duda imponerse sobre las otras familias políticas y convertir la monarquía isabelina en una monarquía de partido. Sin embargo, al hacerlo, al no concebir otro medio de reforzarse como opción política hegemónica que el de reforzar el poder de la Corona, crearon un espacio de competencia muy restringida y muy individualizada que dependía en buena medida de su capacidad para manipular y determinar las acciones del poder real. Sin una ampliación sustancial de la esfera pública liberal, con una concepción estrechamente instrumental y excluyente de la monarquía, el resultado fue la fragmentación interna del propio moderantismo y la extensión indeseada del grado de autonomía política de la reina y de su entorno. Una reina y un entorno para los cuales la ruptura liberal se había visto siempre como una imposición que trataron continuamente de revertir.

Los diversos intentos de deriva autoritaria, con el entusiasta apoyo de la Corona, agudizaron las disensiones internas del moderantismo (un partido en el que convivían antiguos liberales, absolutistas isabelinos y excarlistas) y enlazaron cada vez más con la búsqueda de control de los grandes negocios de la época ligados al poder del Estado. Como en el resto de Europa, el combate contra la corrupción, o incluso la propia idea moderna de corrupción, definida como la incursión ilegítima de los intereses privados en la esfera pública, fue central a la historia de separación entre el Estado y la sociedad civil, y al contrario $^{20}$.

18 Ayguals de Izco (1855); Altadill (1871), y Thompson (2001).

19 Gutiérrez Lloret (2011).

20 Engels y Monier (2014): 13-21. 
En ese ámbito, la visibilidad de la monarquía alcanzó su máxima expresión en las actividades económicas, más o menos fraudulentas, de la exregente María Cristina de Borbón y de su marido morganático, y durante mucho tiempo secreto, Fernando Muñoz. Unas actividades que, además de las concesiones de ferrocarril, incluyeron las explotaciones de minas de mercurio, los fletes de barcos de esclavos, actividades de préstamo privado, modernas lecherías en París, periódicos en Madrid, negocios en Cuba, Puerto Rico y Estados Unidos, etc. La actuación de ambos, compitiendo en condiciones de privilegio con otros actores económicos, fue crucial para la deslegitimación simbólica de la monarquía isabelina y produjo, durante el breve interregno progresista de 1854-56, el primer gran juicio parlamentario por corrupción de la España contemporánea. De hecho, el debate parlamentario que se suscitó entonces en torno a las legítimas o ilegítimas relaciones entre negocios y política fue crucial para la definición moderna de corrupción en la España de la época. Un asunto cuya importancia ya ha sido avanzada pero que requeriría un estudio específico ${ }^{21}$.

Lo que me interesa aquí es analizar la forma en que, en ese laberinto de intereses enfrentados, la «irregular» vida amorosa de la reina Isabel se convirtió, para las diversas facciones del partido moderado y para la propia reina madre, en instrumento político. Tras el affaire Serrano - al que pusieron fin la autoridad combinada de María Cristina de Borbón y del general Ramón Narváez-, el rey consorte mantuvo durante toda su vida una apariencia de reconciliación tan impostada que toda Espańa, y toda Europa, supieron por su boca, y por la de su círculo, de «las locuras de Isabel» y de la dudosa paternidad de sus hijos. Un asunto este último que utilizó hasta el fin de sus días, combinando el chantaje económico privado con las escenas públicas de desaire en las ceremonias de presentación y bautizo de los príncipes. Escenas respondidas por la prensa de oposición con sonoros silencios respecto a algunos de aquellos nacimientos. Se suele decir que para que algo se convierta en un escándalo debe ser, por definición, público. Sin embargo, creo que en la conformación de eso llamado público especialmente, pero no solo, en sociedades con alto niveles de oralidad - debe tenerse muy en cuenta el papel fundamental del rumor amplio y sostenido en una determinada dirección. También su origen, sus formas de diseminación social y de apropiación populares. La conformación de la opinión pública no siempre es pública.

La dama escocesa, Fanny Calderón de la Barca, casada con un político y diplomático español, consideraba que todas las fracciones de la corte y del partido moderado en el poder habían convertido en escandalosa la vida

21 Burdiel (2010) y Casado y Moreno (2014). 
privada de la reina en función de sus propios intereses de patronazgo o políticos. Eran escándalos fabricados y profundamente hipócritas porque, comparado con lo que sucedía en la alta sociedad victoriana de la época, la conducta de las damas de Madrid era asombrosa (y consentidamente) liviana: «Lo más que pueden temer es una separación legal: hay muchas murmuraciones, pero si se mantiene el decoro público, si no hay escándalo público, no hay demasiados problemas». Lo grave y lo peligroso para la propia estabilidad del régimen era la forma en que las rencillas internas por controlar el poder personal de la reina politizaban (y ella politizaba también) la vida íntima y amorosa de Isabel II (y de su marido), convirtiéndola en escandalosa:

[...] están haciendo el juego a sus enemigos. Es la misma vieja historia de la revolución francesa: el descrédito contra la reina comenzó en las clases altas; bajó después al vulgo, y cuando se hubieron desencadenado las pasiones populares, se encontraron los nobles con que eran las primeras víctimas y que no podían contener la tempestad que ellos mismos, sin intención, habían suscitado $^{22}$.

Una opinión que, desde el otro extremo del arco político, compartía José Peris y Valero, un republicano convencido:

Los amigos de Isabel II, los que la abrumaban con adulaciones de todo género, los que la enaltecían con el humo de la lisonja, los que se arrastraban a sus pies como miserables serpientes, los que habían intentado hacer creer al país que su reina era un ángel, son los primeros en publicar las disensiones que habían surgido entre los reales consortes (...) Antes no había ninguna mala pasión; después todo eran malas pasiones. Los palaciegos procuraban soplar el fuego para calentarlas, para encenderlas, para que estallasen, y si era preciso, para que sucumbiera antes que ellos [...] ¿Les convenía la difamación? Sus lenguas se convertían en trompetas que anunciaban a la Espańa, como a la Francia, al interior como al exterior. Hicieron bien, sí, hicieron bien... Así os queremos, $\operatorname{asi}^{23}$.

Personajes tan distantes entre sí como Fanny Calderón de la Barca y José Peris y Valero apuntaban a un fenómeno de impregnación de la esfera pública con una imagen crecientemente sexualizada, brutalizada y desquiciada de la reina (y del rey), envuelta en un discurso moral que, con dosis variables de

22 Calderón de la Barca (1856): 61-62.

23 Peris y Valero (1856): 18. 
cinismo según los sectores que lo alentaron, combinaba la crítica a la corrupción personal, económica, religiosa y política de la corte con formas de refutación fuertemente misóginas y sexistas. Si todos los escándalos redefinen las fronteras entre lo público y lo privado, los que rodearon a los amantes de Isabel II fueron fundamentales para poner en cuestión —en muchas ocasiones inadvertida o indeseadamente- una concepción patrimonial del poder real que permitía a los favoritos de la reina «hacer» política en competencia con los notables liberales elegidos para el Parlamento. De hecho, y como demostró el carácter fugaz del llamado "ministerio relámpago» del marqués de Bedmar (1849), el escándalo suscitado al respecto fue extraordinariamente eficaz para frenar ese tipo de derivas personalistas y aristocráticas ante las cuales cerraban filas incluso los liberales más conservadores como el propio general Narváez. Los mecanismos políticos movilizados para lograrlo fueron, en buena medida, tan opacos y heterodoxos respecto al régimen de publicidad liberal como los utilizados por la Corona y por la Corte. Entre ellos, por ejemplo, la presión personal sobre la reina, utilizando recurrentes formas de chantaje en relación con su vida privada. Un método que usaron, indistintamente, su madre, su marido, el duque de Riánsares, políticos liberales (conservadores) como Narváez o Luis Sartorius, u otros a caballo entre el moderantismo y el antiliberalismo como Donoso Cortés.

\section{APOLO Y DIONISIO: LA CARA OCULTA DEL RÉGIMEN DE PUBLICIDAD MODERNO}

Desde hace ya unos años se ha comenzado a analizar la pornografía política como uno de esos elementos clandestinos, oscuros y dionisíacos que constituían la cara oculta del Apolo de la razón que creía ser la esfera pública liberal. Un mundo de emociones, a menudo rastreras o incluso patológicamente perversas, que ha permanecido mucho tiempo minusvalorado en su capacidad para constituir esa misma esfera pública de una forma mucho más compleja y menos autocomplaciente de lo que se decía entonces y se teorizó después en la estela del trabajo seminal de Jürgen Habermas. Por su propia naturaleza, la documentación al respecto es difícil de rastrear y de interpretar, pero lo que ya sabemos apunta hacia su amplia presencia entre los mecanismos de crítica política en general y sobre la monarquía en particular. El caso más conocido y estudiado es el de la reina María Antonieta, pero materiales similares se han podido encontrar en las últimas décadas del siglo xvin y primeras del siglo XIX sobre los últimos monarcas Hannover, previos al reinado de Victoria; sobre María Luisa de Parma y Godoy; sobre la familia real de 
Nápoles o sobre el mismo papa, en el conflictivo proceso de unificación italiana. Más tarde, en torno al cambio de siglo, fueron escándalos de dimensión europea los relacionados con las actividades del hijo de Victoria, el futuro Eduardo VII, o el famoso affaire Eulenburg en torno a las amistades homosexuales del káiser Guillermo II, estudiadas por Frank Bösch. Estudios similares y diferenciados, de los que ya tenemos algún ejemplo, merecería la evolución de la campaña de difamación de la zarina Alejandra en torno a las diversas fases de la revolución rusa ${ }^{24}$.

A diferencia de lo que ocurre para Francia o Inglaterra, o en períodos posteriores de la historia de Espańa, no tenemos para el reinado isabelino los materiales pornográficos u obscenos que las bibliotecas nacionales de esos países han salvaguardado en las secciones que allí se llaman, respectivamente, Collection de L'Enfer y Private Case. Tenemos, sin embargo, abundantes referencias indirectas de la circulación clandestina de publicaciones eróticas, sobre todo francesas, pero también españolas anónimas, bajo pseudónimos y en imprentas o editoriales que utilizaban nombres y direcciones falsas para eludir la censura, especialmente en Barcelona y Valencia, también en Sevilla y Madrid. Aunque la sátira política de actualidad no era lo predominante en esas obras, sí era muy habitual la burla de la moral convencional y el irreverente anticlericalismo, así como la utilización de lo grotesco, típica del romanticismo, en un momento en que rebeldía moral y política iban muy unidas, como en todos los grandes períodos de cambio. Sabemos que durante toda la época circularon aleluyas, pasquines, álbumes, folletos clandestinos y cartes de visite obscenos, profundamente irreverentes, escatológicos o claramente pornográficos que, en muchos casos, tenían como objeto a los políticos en general $y$ a la corte isabelina en particular ${ }^{25}$.

Mención aparte merece, por su extraordinaria popularidad y difusión entre amplios sectores sociales, el teatro y especialmente la comedia bufa; obras en ocasiones también semiclandestinas o que vivían en el filo de la navaja de la lucha contra la censura. Sobre las obras críticas con la monarquía, representadas durante el reinado de Isabel II, tenemos pocas noticias que no sean indirectas. De su intención y características podemos sin embargo inferir mucho a través de las que se hicieron públicas o se escribieron durante aquella especie de gran catarsis colectiva de liberación que se desató con la revolución de 1868. Se representaron entonces, con gran éxito, obras conocidas como $E l$

24 Véanse, por ejemplo, Goodman (2003): 117-138; McCalman (1993); Calvo (2008); Collins (1985); Domeier (2015); Erber y Robb (1999), y Kolonitskii (2001).

25 Rioyo (2003); Bordería (2004); Martínez y Díez (2007); Domènech (2011), y Guereña (2011). 
padre Claret y Sor Patrocinio de Antonio de Campoamor u otras que lo son menos - por ejemplo, El destronamiento de Isabel II o La corte de Isabel de Borbón de Torres Rojas-, más procaces y de gran éxito de público.

Algunos estudios apuntan que en el teatro republicano de la época (salvo algunas excepciones quizás no tan menores) no hay una auténtica fijación en el cuerpo de la reina y en la reproducción de escenas obscenas explícitas. En términos generales - y a pesar de la latitud de la censura en los momentos revolucionarios-, se ha argumentado que lo que interesaba fundamentalmente a ese tipo de teatro (y a la mayor parte de la publicística más radical del momento) era la denuncia de la opresión del pueblo, de las malas leyes, de la corrupción de los políticos y también del clero; el debate sobre la forma que habría de adoptar el nuevo régimen y las primeras expectativas frustradas. Como aseguró el valenciano Navarro Gonzalvo, el objetivo era «ridiculizar a la monarquía como institución [...] sin perjuro ni calumnia, sin faltar a las severas reglas de la moral y la decencia ${ }^{26}$.

Sin embargo, necesitamos saber mucho más sobre todo ello para aceptar plenamente este punto de vista. No tenemos información suficiente sobre las posibles filiaciones políticas de la crítica de carácter pornográfico, tampoco sobre sus sistemas de comunicación, sobre las formas en que eran emitidos y recibidos mensajes muchas veces crípticos para nosotros, con sobreentendidos y códigos de sentido tan solo comprensibles en la época, sobre la base de relaciones entre redes políticas porosas y transversales y/o empresas económicas y editoriales a menudo fugaces pero reiteradas y relativamente rentables. ¿Cómo se recibían e interpretaban aquellos mensajes? ¿Qué diferencias políticas, de clase y género podía haber en esa recepción? ¿Cómo se transformaban en ideologías y pautas de movilización? ¿Cómo afectaban a la conformación de la opinión pública? Mientras que para el período de la Restauración sabemos mucho más de todo ese mundo semiclandestino, para la etapa isabelina queda casi todo por investigar ${ }^{27}$.

Desde un punto de vista documental, la obra más conocida (y prácticamente la única que se conserva de ese período) es Los Borbones en pelota, una amplia serie de acuarelas compradas en 1986 por la sección de Bellas Artes de la Biblioteca Nacional al representante de un coleccionista privado. Casi todas ellas están firmada por SEM, o a veces por Semen, un pseudónimo bajo el que se acogieron los hermanos Valeriano y Gustavo Adolfo Bécquer así como otros dibujantes, ilustradores y artistas de la época, la mayoría vinculados al

26 De la Fuente (2008): 91 y (2013); Orobon (2017), y Pich (2017).

27 Rioyo (2003); Bordería (2004); Martínez y Díez (2007); Domènech (2011), y Guereña (2011). 
periódico satírico Gil Blas, como Francisco Ortego, Alfredo Daniel Perea, E. Giménez o Vicente Urrabieta ${ }^{28}$. Su temática satírico-política incluía un alto porcentaje de imágenes claramente pornográficas sobre la familia real; su confesor, el padre Claret; sor Patrocinio, la llamada «monja de las llagas»; el último presidente del Consejo de Ministros isabelino, Luis González Bravo; o el notorio amante de la reina antes de la revolución de 1868, Carlos Marfori, entre otros personajes célebres del momento ${ }^{29}$.

La circulación actual de esas acuarelas a través de internet, y su utilización por comentaristas políticos de diverso tipo (especialmente por la extrema derecha antimonárquica) merecerían un comentario en profundidad que no puedo realizar aquí. Baste decir que ahora, como entonces, ese tipo de obras obscenas servía a dos propósitos sobre cuyo enlace merece la pena llamar la atención. Por una parte, ofrecían (y ofrecen) la posibilidad de dar rienda suelta (bajo el paraguas respetable de la crítica política) a los deseos considerados pecaminosos, perversos, a la lujuria condenada por la moral dominante, a las ansias de dominio y/o humillación sexuales, al sexismo, la misoginia y la homofobia ${ }^{30}$. Por otra, servían (y sirven) muy bien al propósito de personalizar, «explicar», acciones políticas de forma primaria, ofreciendo la supuesta clave de su origen más «natural» y secreto, más privado. La "política de dormitorio» es el epítome de la política fuera de control, opuesta al escrutinio y las formas de control ciudadano, tanto en un régimen liberal como democrático. Es la política sometida a las más bajas e inconfesables pasiones, la que repugna y fascina a un tiempo. Esa era (y es) la medida de la eficacia de la pornografía política como lenguaje de deslegitimación global que evita y cancela explicaciones más complejas. Algo que, a mi juicio, puede observarse en la interesada utilización mediática de las publicaciones académicas de Los Borbones en los últimos conflictos políticos, sexuales y de corrupción en torno a la monarquía española de Juan Carlos I y Felipe VI.

En el reinado isabelino, ese enlace entre pornografía y política desvelaba la profunda ansiedad de los liberales de la época hacia un doble y peligroso despliegue de independencia respecto al escrutinio y la autoridad de la nación:

28 El investigador Albert Domènech me ha hecho llegar evidencia convincente para la hipótesis alternativa de que las acuarelas originales fuesen obra colectiva del grupo republicano barcelonés que se reunía en el Café Suizo y al que pertenecían Inocenci López Bernagosi, Tomàs Padró y Josep Lluís Pellicer. De ser comprobada esta hipótesis, que excluiría a los hermanos Bécquer, la interpretación política de Los Borbones en pelota debería ser revisada, al menos en parte.

29 Burdiel (2012).

30 Charnon-Deutsch (1996). 
la independencia política de la monarquía y la independencia del deseo femenino que la reina parecía encarnar. Una doble independencia que era percibida como especialmente peligrosa por una sociedad en plena transición de valores y con un bajísimo grado de consenso entre los actores políticos que se pretendía solucionar, paradójicamente, a través del escudo de la legitimidad monárquica, tanto a nivel simbólico como político. La cuestión por lo tanto supone una compleja interpenetración de factores que se simbolizaban y reforzaban mutuamente.

El tratamiento que recibe Isabel II en Los Borbones tiene amplias concomitancias pero también varias diferencias respecto al que recibieron María Antonieta, Sofía de Nápoles o la zarina Alejandra. En el primero y el último de los casos, con la revolución ya en marcha, fue necesario bestializar a ambas, convertirlas en mujeres infames, monstruos devoradores de la patria y de sus «hombres» para poder luego juzgarlas y ejecutarlas. La atribución de una sexualidad aberrante se combinaba con su perversa capacidad para la manipulación secreta de los reyes (débiles y humillados) que trastocaría las naturalezas femenina y masculina, convirtiéndolas a ellas en las verdaderas detentadoras del poder públicamente atribuido a sus maridos. Una fantasía de engaño, manipulación y feminización de la política que buscaba de forma explícita excitar el sexismo y la misoginia en torno al poder público, y en parte también privado, de las mujeres reinas.

También, la reina española aparece representada en estas acuarelas como una Eva lasciva, completamente fuera de control, el alter ego del ángel doméstico o la madre cristiana que constituían los modelos de feminidad dominantes en la época. Su supuesta ninfomanía servía, a un tiempo, para simbolizar el poder aberrante de la monarquía (a través de la aberrante independencia y poder sexual de la reina) y para dar rienda suelta — tras el formato respetable de la crítica política- a la misoginia y a las fantasías más o menos perturbadoras que aquellos sublimes modelos de feminidad cancelaban y suprimían. Sexo en grupo, sodomía, escenas lésbicas, felaciones, zoofilia, etc., se suceden en las viñetas pornográficas sobre Isabel II producidas entre 1868 y 1869. De esta forma, la crítica política a la actuación del monarca era suplantada, devorada y sometida a la denigración brutal de una hembra desenfrenada, sexualmente hiperactiva, incontrolable. Esas imágenes pornográficas no tenían por supuesto un carácter descriptivo, aunque fuese posible encontrar crédulos y alarmados ciudadanos que diesen crédito a las relaciones sexuales de Isabel II con su confesor, con sor Patrocinio o con un asno. Tenían sobre todo un carácter simbólicamente performativo: una vez que se podía decir, hacer, ese tipo de alusiones, era posible justificar todo lo que se pudiera hacer en el ámbito político respecto a la reina. 
A diferencia de María Antonieta o la zarina Alejandra, o María Luisa de Parma, Isabel II era una reina propietaria. No necesita servirse de su cuerpo y de su capacidad de seducción y manipulación del deseo masculino para alcanzar el poder. En nombre propio podía convocar la sumisión y los deseos (de poder) de los hombres que la rodeaban y adulaban, que satisfacían «sus deseos». La reina Isabel se convierte así no solo en una extranjera a la nación, sino en un hombre, en algo tan monstruoso como "un Luis XV hembra». Un sujeto al tiempo activo y pasivo. Frente a ella, se dibuja la humillación constante de la figura de rey, apelando a terrores masculinos clásicos como la castración, la imagen del cornudo, la usurpación literal y simbólica del miembro viril, la degradación completa de la autoridad y la dignidad masculinas. El marido engańado y afeminado, que se humilla y consiente, no puede conducir más que a la perversión moral, a la completa y esencial corrupción del cuerpo político y social. Una novela que se hizo popular en esos años, La chula. Historia de muchos (1870), recoge todos los rumores sobre la homosexualidad del rey que, junto a la «vil prostituta real», ultraja a la nación. Al final, lo que está en juego es la honra de los buenos españoles, que hicieron la revolución de 1868 para poder hablar de lo que era su territorio propio, la política y el poder, sin necesidad de ruborizarse ante sus madres, sus esposas y sus hijas. Honra y deshonra dependen, por lo tanto, de una reformulación moral conjunta de los espacios y valores privados y públicos.

Hay algunos aspectos que diferencian, al menos en parte, el tratamiento que recibe Isabel II respecto a las otras reinas consortes. Singularidades que, a mi juicio, no solo obedecen a la evolución artística del género entre finales del XVIII y mediados del XIX. Me refiero a la fuerte connotación bufa y carnavalesca de las acuarelas de SEM. Isabel II carece de la belleza perversa, sofisticada y temible de la reina francesa o de la rusa. No tiene tampoco su inteligencia refinada. Es un cuerpo desprovisto de gracia, grueso y fofo, casi cómico y circense. La reina Isabel es animalizada (como también lo fue María Antonieta) pero en un sentido que no la convierte en un monstruo temible sino en una bestia degradada que inspira desprecio y repulsión, risa a lo más. Es una figura de expresión ausente, indiferente o estúpida. Un animal que se entrega a sus placeres brutales e indiscriminados con la mirada perdida e inexpresiva. Es la antítesis total de toda pasión y de toda delicadeza femeninas. Un personaje de circo o carnaval, puramente grotesco y obsceno que si induce a alguna reacción grata, es a la carcajada.

Aquí reside, a mi juicio, la otra gran diferencia respecto a las representaciones de María Antonieta y de la zarina Alejandra. Isabel II no va a ser ejecutada; no lo ha sido en el momento en que se producen esas acuarelas soeces, ni en ningún momento anterior se preveía que fuera necesario hacerlo. El 
exilio era suficiente y, una vez en él, la ridiculización, la degradación. En Los Borbones - con su recurso constante a las escenas circenses, teatrales, de marionetas y carnaval - hay una visión bufa, acorde con el culto posromántico a lo grotesco y a la risa sardónica, cruel, ligeramente siniestra pero nunca dramática o trágica, como la que se aprecia en las imágenes postreras de María Antonieta y Alejandra. Frente al refinamiento de aquellas, la imagen de Isabel II va quedando fijada popularmente como la representación de la estulticia, del capricho, la volubilidad, la indolencia, la grosería personal, la superstición milagrera, la animal incapacidad para distinguir entre el bien y el mal, la torpeza, lo feo y lo burdo, lo ordinario, pero nunca lo trágico y lo sublime ${ }^{31}$.

La diferencia será crucial para la evolución de la imagen de la propia Isabel II, pero también de la dinastía, favoreciendo que esta pudiese «regenerarse», seis años después, en el rey-soldado que fue Alfonso XII. Porque al final, la reina Isabel es simplemente una torpe y risible prostituta de cabaret que se ha disfrazado de reina. Lo que significan la verdadera realeza y la auténtica monarquía, así como la auténtica posición e identidad de las mujeres, queda a salvo. Tan solo hay que esperar a que acabe el carnaval. Con ello entro en mis últimas consideraciones sobre los materiales culturales y políticos que fabricaron el mensaje más subliminal, y efectivo a mi parecer, de «los escándalos de Isabel II».

\section{TRANSGRESIÓN Y REACCIÓN. MATERIALES DE ESTUDIO}

Desde Mijail Bajtin se ha reflexionado mucho sobre la forma en que lo carnavalesco trastoca las identidades y las jerarquías fijas de identidad sexual y de poder, pero también las refuerza y asienta en la medida en que su inversión o transgresión es lo que permite la burla, el escarnio y el escándalo. No cuestiona necesariamente las asunciones morales más convencionales, las confirma. De la estabilidad subyacente de la convención depende la posibilidad y eficacia de su transgresión cómica. El carnaval es un mecanismo de subversión y crítica pero también una válvula de escape para momentos de conflicto y/o de impotencia políticos. Los elementos transgresores de lo grotesco no implican automáticamente una crítica progresista a lo existente, ni desde el punto de vista político ni desde el punto de vista moral ${ }^{32}$.

En los que respecta al primero de esos puntos de vista, creo que en Los Borbones coexisten planteamientos diversos que oscilan entre el nihilismo

31 Burdiel (2012).

32 Bajtin (1998) y Stallybrass y White (1986). 
derrotista, el cinismo político global y potencialmente reaccionario y la crítica republicana y radical ante la preeminencia de progresistas y unionistas monárquicos en el Gobierno tras la revolución de 1868. Sin embargo, si entendemos la política en el sentido más amplio que vengo proponiendo, la lectura de estos materiales, sus implicaciones a mi juicio potencialmente muy reaccionarias, se hacen más complejas e interesantes. Revelan de qué manera los patrones de significado cultural asociados a los modelos imperantes (y fuertemente interrelacionados) de madre cristiana, ángel del hogar o ciudadana virtuosa podían ser utilizados (en su brutal inversión) como símbolos de la corrupción y la perversión del cuerpo político en su conjunto. Por ello, el hecho de que el primer monarca netamente constitucional de la historia de Espańa fuese una mujer, con una vida privada considerada de forma creciente como escandalosa, no puede ser contemplado como un hecho neutro o sin significación política relevante. Como tampoco lo es que, en los momentos cruciales de crisis de la monarquía absoluta en toda Europa (véase para España el caso de María Luisa de Parma y Godoy), se generalizase la crítica a las reinas libertinas y poderosas y a los reyes débiles y afeminados. Encarnación ambos de la aberración moral de un régimen corrompido y corruptor contra el que la revolución habría de medir sus fuerzas ${ }^{33}$. Un planteamiento que permite analizar esos escándalos sobre las reinas, consortes o propietarias como "ceremonias estatutarias» de transformación social, algo más que epifenómenos: fenómenos creativos en sí mismos ${ }^{34}$.

Comparto con Vivian R. Gruder la inquietud por las formas de hipérbole verbal que pueden acabar haciendo suponer que la Revolución francesa —o en el caso que me ocupa, la revolución española de 1868 - fueron producto de los escándalos sobre la vida sexual de la reina María Antonieta o de Isabel II. Más aún, que la supuesta vida licenciosa de ambas y sus diversas maneras de desestabilizar los patrones de feminidad dominantes fueron la causa última de la revolución ${ }^{35}$. Como he intentado ir desarrollando a lo largo de este texto, la cuestión es mucho más compleja. En ella, los datos objetivos sobre las actividades sexuales de las reinas tienen valor histórico y cultural (también aquí en su sentido más amplio) en tanto que fueron fabricados y representados en la esfera pública al hilo de conflictos que afectaban a muchos otros factores como la corrupción económica, el exclusivismo de partido, las restricciones a la participación ciudadana, las amenazas de reacción política, etc.

33 Cosandey (2000) y Calvo (2008).

34 De Blic y Lemieux (2005).

35 Gruder (2002). 
El hecho de que los valores culturales asociados a las mujeres respetables fuesen utilizados para legitimar o deslegitimar una determinada institución, en este caso la monarquía constitucional, no nos puede llevar a suponer que la conducta concreta de estas (en un sentido o en otro de lo que llamemos «objetivo») fuese la responsable última, la clave de bóveda, de la acción política. Las formas de imbricación al respecto son simbólicas en su manifestación más profunda. Es decir, se refieren a patrones de significado (incluyendo los referidos a la masculinidad y la feminidad) que permitían que la representación pública de esas supuestas conductas se convirtiese en eco significativo de todo lo demás. En otras palabras, que pudiesen ser un arma de combate capaz de legitimar o no a la monarquía constitucional entendida no solo como una institución política, sino cultural.

Es en este punto en el que creo que merece la pena una reflexión final sobre el juego de espejos que pudo producirse en la época entre materiales tan dispares entre sí como la pornografía política (consumida mayoritariamente por hombres) y la llamada ficción doméstica destinada a la moralización y educación de las mujeres de autoras tan populares durante el reinado isabelino como Ángela Grassi, Pilar Sinués o Faustina Sáez de Melgar. En sus novelas (muchas de ellas auténticos best sellers de la época), pero también en la prensa y en las obras más directamente de instrucción moral, estas autoras desempeñaron un papel destacadísimo en la conformación de la identidad de las clases medias españolas en torno a la ideología de la domesticidad.

No puedo entrar aquí en una valoración detallada de esa ficción doméstica que ya han estudiado en profundidad autoras como Alda Blanco e Isabel Molina. Esta última, especialmente, ha propuesto la importancia de analizar las decisivas connotaciones políticas de la ficción doméstica en tanto que conformadora de lo privado como horizonte de la plena realización personal y, al mismo tiempo, instrumento fundamental de moralización del orden social postrevolucionario ${ }^{36}$. Como demostró el llamado Manifiesto de España con honra, en ese universo de virtud privada y cívica la familia se construye como clave de bóveda del nuevo orden liberal, asentada sobre la complementariedad (jerárquica) entre los sexos lograda a través del matrimonio (por amor y afinidad) entre una mujer casta, abnegada, discreta, sensible y piadosa que contribuye decisivamente en la educación de ciudadanos virtuosos, y un hombre que combina su virilidad y su proyección en el espacio público con su atención a lo doméstico, su condición de "hombre sentimental», esposo y padre. Esa ficción para las clases medias podía servir de puente cultural e identitario respecto a su propia heterogeneidad interna oponiéndose a la corrupción, el

36 Blanco (2001) y Molina (2015). 
despilfarro, la amoralidad, la brutalidad y la falta de sensibilidad tanto de la aristocracia como del populacho.

Los escándalos sexuales sobre la familia real, los que produjeron affaires y los que se quedaron en rumores, eran el lado oscuro y necesario del espejo de virtud en que quería mirarse una burguesía insegura de sí misma, que buscaba mecanismos de construcción y justificación de su superioridad simbólica y política, de su capacidad para apropiarse en ambos aspectos de la monarquía como símbolo de la nación. Vistas así las cosas, las escritoras virtuosas isabelinas, al menos en parte, contribuyeron a crear el espacio de significación de esa pornografía política, al igual que ocurrió en otros países de Europa, comenzando por Inglaterra ${ }^{37}$. La ficción doméstica fue parte esencial del conglomerado de materiales culturales que construyó el universo de valores que permitió la demonización de la reina Isabel, su expulsión del cuerpo de la nación, su brutal sexualización como la Eva lasciva de un mundo que debía acabar con ella. Al mismo tiempo que, en privado, recopilaba con fruición materiales sobre los amantes de la reina y las posibilidades de paternidad de sus hijos, Cánovas del Castillo, el autor de la Restauración borbónica de 1874, le negaba a Isabel II su vuelta del exilio porque «V.M. no es una persona, es un reinado, es una época histórica, y lo que el país necesita es otro reinado y otra época histórica diferente de las anteriores", tanto en lo político como en lo moral ${ }^{38}$.

En este terreno de análisis, tan prometedor en principio, siguen existiendo los escollos, difíciles de salvar, de las pautas y modos de recepción de los mensajes que he propuesto como pertinentes. Por lo que respecta a la novelas, sabemos muy poco de las prácticas de lectura en un momento en que esta iba configurándose cada vez más como un acto privado. Sin embargo, por analogía con lo que conocemos a través de otros estudios - por ejemplo, el ya clásico de Judith Lyon-Caen sobre los usos políticos de la novela en tiempos de Bal$\mathrm{zac}^{39}$ - podemos vislumbrar todo un mundo oculto para los estudios centrados exclusivamente en las formas más clásicas del régimen de publicidad moderno. El mundo de las tertulias y de las trastiendas, de las lecturas en grupo de hombres y de mujeres, de los debates a veces ardientes sobre las relaciones entre realidad y ficción. Incluso, si apuramos las fuentes, las correspondencias privadas entre las lectoras (utilizo intencionadamente el femenino) y entre estas y sus autoras favoritas, podemos comenzar a vislumbrar la forma en

\footnotetext{
Clark (2004); Erber y Robb (1999); Maza (1997), y Shulte (2002).

38 Real Academia de la Historia, Archivo privado de Isabel II, leg. 9/9655, Antonio Cánovas a Isabel II, 30 de abril de 1875.

39 Lyon-Caen (2006) y Lyon-Caen y Ribard (2010).
} 
que vida y lectura se cruzaban. La manera en que se negociaban y reconfiguraban las identidades en el proceso de la lectura, cómo las novelas y el teatro podían ( $\mathrm{y}$ pueden) ayudar a descifrar la realidad, a retrazar itinerarios vitales o a confirmarlos, ensancharlos o complicarlos ${ }^{40}$. Las novelas, el teatro y, también, esa otra forma de ficción con efectos de verdad que fue la pornografía política.

\section{Y UNA SERIE DE PREGUNTAS}

Una propuesta de estudio como esta no puede concluir más que con preguntas. Preguntas referidas, por ejemplo, a la manera en que la ideología de la domesticidad y los valores de sensibilidad, discreción, armonización de intereses y mediación atribuidos a las mujeres podían trasvasarse simbólicamente a la monarquía constitucional. ¿Era la monarquía constitucional decimonónica - como ha escrito David Cannadine - una monarquía emasculada, una versión feminizada de una institución esencialmente masculina, lo que queda «cuando el soberano es privado de las funciones masculinas históricas de dios, gobernante y general en jefe y se enfatizan — quizás por defecto o quizás intencionadamente - la familia, la domesticidad, la maternidad y el glamour»? ${ }^{21}$. En esa perspectiva tiene cada vez más interés el debate actual sobre la potencia de la imagen del ángel doméstico en la Espańa decimonónica, y más precisamente isabelina. Las formas en que confluía, reforzaba o entraba en conflicto con las de la madre cristiana, la mujer fuerte de la Biblia o la ciudadana virtuosa ${ }^{42}$. Sabemos bastante ya sobre el carácter retórico e instrumental que, desde la Ilustración, tuvo la reivindicación de un espacio íntimo protegido frente a la mirada del público. Sabemos también sobre las formas de transgresión y contaminación de lo público por lo privado, pero sabemos menos sobre el fenómeno inverso: la impregnación de lo privado por lo público, su conversión en un espacio político por derecho propio.

Por otra parte, pero en estrecha relación, necesitamos saber más, y más en concreto, sobre a qué sectores sociales y políticos sirvió la demonización escandalosa de Isabel II. De qué forma aquellos escándalos ocultaron otros relativos a la corrupción económica y política durante el reinado isabelino, favoreciendo el trasvase de élites y forjando para ellas un puente que, tras el gran trauma del llamado Sexenio Revolucionario, las integró en el régimen de la Restauración a partir de 1874. Preguntas que enlazan con otras relativas a

\footnotetext{
40 Burdiel (2015).

41 Cannadine (2004): 24.

42 Romeo (2014) y Mínguez (2016).
} 
los moldes culturales y simbólicos, relacionados con lo masculino y lo femenino, que ayudaron a consolidar la monarquía constitucional «regenerada» de la Restauración. ¿El énfasis en la virilidad (militar) y la vida amorosa extramatrimonial de Alfonso XII y Alfonso XIII deslegitimó o legitimó la imagen del monarca masculino? ¿Cuándo y en qué contextos políticos hizo una cosa $\mathrm{u}$ otra? ¿Por qué fue «necesaria» la Restauración borbónica y fracasó la monarquía democrática de Amadeo? ¿Por qué no funcionó su imagen de caballero y hombre doméstico, esposo y padre, como no lo hizo tampoco el dechado de virtudes domésticas de su esposa ${ }^{243}$ ¿Qué nos dice el rechazo político, pero también simbólico, del matrimonio Saboya respecto a la nacionalización de la monarquía española? ¿Sobre qué moldes culturales y de género, sobre qué tipo de "pueblo", se produjo esta en realidad? Respecto a todo ello necesitamos respuestas cada vez más complejas y matizadas que, a su vez, permitan iluminar desde el pasado, sin anacronismos, controversias actuales sobre la monarquía en un contexto democrático, muy lejano políticamente pero quizás no tanto culturalmente, de la monarquía constitucional del siglo XIX.

En este artículo no he intentado otra cosa que recorrer preguntas clásicas, intentar rehacerlas al menos en parte y proponer respuestas provisionales que conduzcan, en el mejor de los casos, a otras preguntas mejor formuladas y espero que más sagaces. Estoy convencida, en todo caso, de que para ello será necesaria la ampliación de nuestra noción de «lo político» y de que los escándalos sexuales o de corrupción — con su fuerte carácter estratégico e imprevisible - ofrecen para este ámbito un potencial heurístico de primer orden. Por lo pronto, y para el caso español, su análisis descarta una lectura superficial que identifique «los escándalos de Isabel II», la pornografía política suscitada en torno a los mismos o la obra de las llamadas «escritoras virtuosas», con un déficit de modernidad. Por el contrario, todo ello apunta a un proceso transeuropeo de características muy similares y plenamente moderno, con todas sus ambivalencias morales y toda su imprevisibilidad política.

\section{Bibliografía}

Altadill, A. (1871). La Canalla. Novela de costumbres aristocráticas. Madrid: Imp. de R. Labajos.

Anderson, B. (1993) [1983]. Comunidades imaginadas. Reflexiones sobre el origen y la difusión del nacionalismo. México: Fondo de Cultura Económica.

Anónimo. (1854). Escándalos de Isabel II. Buenos Aires: s.e.

43 Gutiérrez et al. (2014). 
Ayguals de Izco, W. (1855). El palacio de los crimenes o el pueblo y sus opresores. Tercera y última época de María. Madrid: Imp. de D. W. Ayguals de Izco.

Bajtin, M. (1998) [1941]. La cultura popular en la Edad Media y el Renacimiento: El contexto de François Rabelais. Madrid: Alianza.

Banerjee, M., Backerra, C. y Sarti, C. (eds.). (2017). Transnational Histories of the Royal Nation'. London: Palgrave. Disponible en: https://doi.org/10.1007/978-3-319-50523-7. (1998) [1992]. Talking of the Royal Family. London: Routledge.

Blanco, A. (2001). Escritoras virtuosas. Narradoras de la domesticidad en la España isabelina. Granada: Universidad de Granada.

Blanco Valdés, R. L. (2010). La construcción de la libertad. Madrid: Alianza Editorial.

Bordería, E. (2004). Política, cultura y sátira en la España isabelina: José Bernat y Baldoví. Valencia: Institució Alfons el Magnànim.

Brice, C. (2010). Monarchie et identité nationale en Italie (1861-1900). Paris: Éditions de l'École des Hautes Études en Sciences Sociales.

— y Moreno Luzón, J. (eds.). (2013). Monarchia, nazione, nacionalismo in Europa (18301914). Memoria e Ricerca, 42, monográfico.

Burdiel, I. (2010). Isabel II. Una biografía. Madrid: Taurus.

(2012). Los Borbones en pelota. Zaragoza: Institución Fernando el Católico.

(2015). Lo que las novelas pueden decir a los historiadores. Notas para Manuel Pérez Ledesma. En J. Álvarez Junco, R. Cruz y F. Peyrou (eds.). El historiador consciente. Homenaje a Manuel Pérez Ledesma (pp. 263-282). Madrid: Marcial Pons.

Burr Margadant, J. (2006). Representing Queen Marie-Amélie in a 'Bourgeois' Monarchy. Historical reflections/Reflexions Historiques, 32 (2), 421-451.

Calderón de la Barca, F. (1856). The Attaché in Madrid: or Sketches of the Court of Isabella II. New York: D. Appleton \& Co.

Calvo, J. (2008). M.a Luisa de Parma: Reina de España, esclava del mito. Granada: Universidad de Granada.

Campbell Orr, C. (2007). The feminization of the monarchy, 1780-1910: Royal masculinity and female empowerment. En A. Olechnowicz (ed.). The Monarchy and the British Nation, 1780 to the Present (pp. 76-107). Cambridge: Cambridge University Press.

Cannadine, D. (1983). The context, performance and meaning of ritual. The British Monarchy and the 'invention of tradition', c. 1820-1977. En E. Hobsbawm y T. Ranger (eds.). The invention of tradition (pp. 101-164). Cambridge: Cambridge University Press.

- (2004). From biography to history: Writting the modern British monarchy. Historical Research, 197 (77), 289-312. Disponible en: https://doi.org/10.1111/j.1468-2281.2004. 00211.x.

Capellán, G. (2015). El escenario de las culturas políticas: Régimen de publicidad y metáforas de la opinión pública. En C. Forcadell y M. Suárez Cortina (coords.). La Restauración y la Repúlbica, 1874-1936. Vol. III. Historia de las culturas politicas en España y América Latina (pp. 111-140). Madrid y Zaragoza: Marcial Pons y Prensas de la Universidad de Zaragoza.

Casado, M. A. y Moreno, M. (2014). María Cristina de Borbón y María Cristina de Habsburgo: dos regentes entre los modos de vida aristocráticos y burgueses. Historia y Politica, 31, 113-138. 
Charnon-Deutsch, L. (1996). The pornographic Subject of Los Borbones en Pelota. En D. William Foster (ed.). Bodies and Biases: Sexualities in Hispanic Cultures and Literatures (pp. 274-293). Minneapolis: University of Minessota Press.

Clark, A. (2004). Scandal. The sexual politics of the British constitution. Princeton and Oxford: Princeton University Press.

Collins, C. (1985). Photography and Politics in Rome. The Edict of 1861 and the Scandalous Montages of 1861-1862. History of Photography, 9, 295-303. Disponible en: https://doi. org/10.1080/03087298.1985.10443027.

Cosandey, F. (2000). La reine de France: Symbole et pouvoir (XVe-XVIIIe siécle). Paris: Gallimard.

De Blic, D. y Lemieux, C. (2005). Le scandale comme épreuve. Elements de sociologie pragmatique. Politix, 18 (71), 9-38. Disponible en: https://doi.org/10.3917/pox.071.0009.

De la Fuente, G. (2008). El teatro republicano de la Gloriosa. Ayer, 72, 83-119.

- (2013). El teatro político en la España del siglo XIX. Historia y Política, 29, monográfico.

Deploige, J. (ed.). (2007). Mystifying the Monarch: Studies on Discourse, Power, and History. Amsterdam: Amsterdam University Press.

Domeier, N. (2015). The Eulenburg Affair. A Cultural History in the German Empire. Rochester: Camdem House.

Domènech, A. (2011). Apuntes para la historia de la ilustración erótica y pornográfica en la España del siglo XIX. Tebeosfera, 9 (2. ${ }^{a}$ época). Disponible en: http://www.tebeosfera.com.

Engels, J. I. y Monier, F. (eds.). (2014). Scandales et corruption politique à l'époque contemporaine (XIXe-XXe siècles). Paris: Armand Colin.

Erber, N. y Robb, G. (eds.). (1999). Disorder in the Court: Trials and Sexual Conflicts at the Turn of the Century. New York: New York University Press. Disponible en: https://doi. org/10.1057/9781403934314_1.

Fradenburg, L. O. (ed.). (1992). Women and Sovereignity. Edinburgh: Edinburgh University Press.

Goodman, D. (2003). Marie-Antoinette. Writings on the Body of a Queen. New York and London: Routledge.

Gruder, V. R. (2002). The Question of Marie-Antoinette: The Queen and the Public Opinion before the Revolution. French History, 16 (3), 269-298. Disponible en: https://doi. org/10.1093/fh/16.3.269.

Guereña, J.-L. (2011). Un infierno español. Un ensayo de bibliografía de publicaciones eróticas españolas clandestinas (1812-1939). Madrid: Libris.

Gutiérrez Lloret, R. A. (2011). Isabel II, de símbolo de la libertad a deshonra de Espańa. En E. La Parra (coord.). La imagen del poder. Reyes y regentes en la España del siglo XIX (pp. 221-282). Madrid: Síntesis.

— Mira Abad, A. y Moreno Seco, M. (eds.). (2014). Las reinas y la legitimidad de la monarquía en España, siglos XviI-Xx. Historia y Política, 31, monográfico.

Hobsbawm, E. y Ranger, T. (eds.). (2002) [1983]. La invención de la tradición. Barcelona: Crítica.

Homans, M. (1998). Royal Representations. Queen Victoria and British Culture, 1837-1876. Chicago: Chicago University Press. Disponible en: https://doi.org/10.7208/chicago/ 9780226351155.001 .0001 . 
Kirsch, M. (1999). Monarch und Parlament im 19 Jahrhundert. Der monarschische Konstitutionalismus als europäischer Verfassungstyp-Frankreich im Vergleich. Göttingen: Vandenhoeck \& Ruprecht.

Kolonitskii, B. (2001). La desacralización de la monarquía: Los rumores y la caída de los Romanov. En VV. AA. Interpretar la revolución rusa. El lenguaje y los simbolos de 1917 (pp. 27-51). Valencia y Madrid: Biblioteca Nueva-Universitat de València.

Langewiesche, D. (2012). La monarquía en el siglo de la nación burguesa. En J. Millán y M. C. Romeo (eds.). La época del Estado-nación en Europa (pp.119-132). Valencia: PUV.

Lilti, A. (2014). Figures publiques. L'invention de la celebrité, 1750-1850. Paris: Fayard.

Lyon-Caen, J. (2006). La lectura et la vie. Les usages du roman au temps de Balzac. Paris: Tallandier.

— y Ribard, D. (2010). L'historien et la littèrature. Paris: La Découverte.

Martínez, A. L. y Díez, J. I. (2007). Venus Veneranda II: Literatura erótica y modernidad en España. Madrid: Editorial Complutense.

McCalman, I. (1993). Radical Underworld. Prophets, Revolutionaires and Pornographers in London, 1795-1840. Oxford: Clarendon Press.

Maza, S. (1997). Vies privées, affaires publiques. The causes célèbres of prerevolutionary France. Paris: Fayard.

Mínguez, R. (2016). Evas, Marías y Magdalenas. Género y moral católica en la España liberal (1833-1874). Madrid: CEPC.

Molina, I. (2015). La ficción doméstica: Ángela Grassi, Pilar Sinués y Faustina Sáez. Una aproximación a las imágenes de género en la España burguesa [tesis doctoral inédita]. Universitat de València.

Morayta, M. (1893-1894). Historia general de España, desde los tiempos antehistóricos hasta nuestros días, vol. VII. Madrid: Felipe González Rojas.

Munich, A. (1996). Queen Victoria's Secrets. Cambridge: Cambridge University Press.

Orobon, M. A. (2017). Una gloriosa revolución: prensa satírica ilustrada y afirmación militante (1868-1870). En D. A. González, M. Ortíz Heras y J. S. Pérez Garzón (eds). La historia, lost in translation? Actas del XIII Congreso de la Asociación de Historia Contemporánea (pp. 1065-1075). Cuenca: Universidad de Castilla La Mancha.

Peris y Valero, J. (1856). El proceso de los Borbones. Madrid: Imprenta de la Regeneración.

Pich, J. (2017). La Gloriosa y la radicalización de la sátira. Tomás Padró, La Flaca y la cultura política republicana. En D. A. González, M. Ortíz Heras y J. S. Pérez Garzón (eds.). La historia, lost in translation? Actas del XIII Congreso de la Asociación de Historia Contemporánea (pp. 1077-1089). Cuenca: Universidad de Castilla La Mancha.

Plunkett, J. (2002). Queen Victoria: First Media Monarch. Oxford: Oxdord University Press.

Rioyo, J. (2003). La vida golfa. Historia de las casas de lenocinio, holganza y malvivir. Madrid: Aguilar.

Romeo, M. C. (2014). Domesticidad y política. Las relaciones de género en la sociedad posrevolucionaria. En M. C. Romeo y M. Sierra (coords.). La España liberal, 1833-1874. Vol. II. Historia de las culturas politicas en España y América Latina (pp. 89-127). Madrid y Zaragoza: Marcial Pons y Prensas Universitarias de Zaragoza.

Rosanvallon, P. (1994). La monarchie impossible. Paris: Fayard. 
Shulte, R. (2002). The Queen. A Middle Class Tragedy: The Writing of History and the Creation of Myths in Nineteenth-Century France and Germany. Gender and History, 2 (14), 266-293. Disponible en: https://doi.org/10.1111/1468-0424.00266.

Stallybrass, P. y White, A. (1986). The Politics and Poetics of Transgression. Ithaca: Cornell University Press.

Thompson, J. B. (2001). Los escándalos sexuales en la esfera política. En J. B. Thompson. El escándalo político. Poder y visibilidad en la era de los medios de comunicación (pp. 167-218). Barcelona: Paidós.

Unowsky, D. L. (2005). The Pomp and Politics of Patriotism. Imperial Celebrations in Habsburg Austria, 1848-1916. West Lafayette: Purdue University Press.

Valera, J. (2002). Correspondencia. Vol. I (1847-1861). Madrid: Castalia. 